\title{
EL RECARGO EN EL IMPUESTO MUNICIPAL SOBRE LA RA- DICACION EN LOS ESTABLECIMIENTOS INDUSTRIALES EMPLAZADOS FUERA DE LAS ZONAS SENALADAS PARA TAL FIN EN LOS PLANES Y NORMAS URBANISTICAS
}

(Comentarios a la Sentencia del Tribunal Supremo, Sala 3.", de 6 de marzo de 1987)

\author{
por \\ Antonio Longas Lafuente \\ Técnico de Administración General
}

\section{PLANTEAMIENTO GENERAL}

La Sentencia del Tribunal Supremo (Sala III) de 6 de marzo de 1987 ha venido a incidir en un tema poco debatido por la doctrina y la jurisprudencia, pero de una gran incidencia no sólo en las Haciendas municipales, sino también en el planeamiento urbanístico de las ciudades.

Se trata del recargo de hasta un 30 por 100 sobre la cuota líquida del Impuesto Municipal sobre la Radicación en unos establecimientos concretos.

En el comentario de esta sentencia y del artículo $329.1 .^{\circ}$ del Real Decreto legislativo 781/1986, de 18 de abril, va a centrarse este examen.

Dicho artículo dispone que: «1. Los Ayuntamientos podrán establecer en las Ordenanzas respectivas recargos de hasta un 30 por 100 sobre las cuotas liquidadas por el impuesto (se refiere al de Radicación) cuando los establecimientos industriales estu- 
vieren emplazados fuera de las zonas señaladas para tal fin en los planes y normas urbanísticas, o en las ordenanzas reguladoras de las actividades molestas, insalubres, nocivas y peligrosas. 2. La aplicación de este recargo sancionador no quedará afectada por la limitación impuesta en el artículo anterior.»

La problemática planteada por la aplicación de este artículo requiere precisar una serie de aspectos concretos, como son:

a) Finalidad de la norma.

b) Interpretación de sus conceptos: «establecimientos industriales"; emplaazmiento "fuera de las zonas señaladas para tal fin en los planes y normas urbanísticas, o en las ordenanzas reguladoras de las actividades molestas, insalubres, nocivas y peligrosas».

c) Aplicación concreta en relación con los Planes de Urbanismo.

\section{FINALIDAD DE LA NORMA}

La finalidad del recargo establecido por este artículo 329 del Real Decreto legislativo $781 / 1986$ ha venido a ser precisado por la jurisprudencia, y así, concretamente la Sentencia del Tribunal Supremo de 6 de marzo de 1987 (Sala III) señala que:

«El recargo forma parte de la deuda impositiva, con finalidad no recaudatoria sino extraoficial y consiste en conseguir indirectamente, mediante el aumento de la presión fiscal, que desaparezcan de su emplazamiento actual aquellas actividades comerciales $o$ industriales inadecuadas a la ordenación urbanística.»

La interpretación que de la norma lleva a cabo esta sentencia tiene gran importancia para el examen que se realiza y a ella acudiremos con reiteración. Basta considerar de momento si es ésa la finalidad que en todo caso pretenderían los Ayuntamientos con la aplicación de la norma: no los fines recaudatorios, sino los de lograr el traslado de los establecimientos inadecuados a la ordenación urbanística (con la problemática que ello conlleva y que se analizará).

Se trata, por tanto, de una finalidad extraoficial y no recaudatoria la que impregna a este artículo. En última instancia nos encontramos ante un recargo que coadyuva a los fines urbanísticos 
del Municipio en concreto. Y aunque la sentencia del Tribunal Supremo señale que con ello se pretende que desaparezcan de su emplazamiento actual aquellas actividades comerciales o industriales inadecuadas a la ordenación urbanística, se entiende esta pretensión como excesiva por cuanto, en tódo caso, la finalidad no es tan puntual como específica la sentencia, sino que se trataría de lograr la adecuación de las actividades a la ordenación urbanistica.

El Tribunal Supremo al seguir esta interpretación mantiene así una aplicación estricta del artículo $60.4 .^{\circ}$ del vigente Texto Refundido de la Ley del Suelo, que «adopta la fórmula simplista de la demolición al decir que cuando la disconformidad con el Plan no impida la edificación en el mismo solar que ocupa el edificio, el propietario podrá demolerlo sometiéndose al Plan de ordenación" (Sentencia del Tribunal Supremo, Sala IV, de 17 de febrero de 1981). Ahora bien, la adaptación de los edificios fuera de ordenación al régimen legal vigente, puede exigir no la demolición total, sino tan sólo de la parte del edificio que resulte suficiente para situar el edificio dentro de las condiciones exigidas por el Plan de Ordenación; o incluso puede no precisar su demolición.

De otra parte, el Tribunal Supremo sigue así también la línea jurisprudencial que vincula la declaración de ruina del artículo $183.2 .^{\circ}-c$ ) de la Ley del Suelo (circunstancias urbanísticas que aconsejaren la demolición del inmueble) al artículo 60 de la misma Ley.

La finalidad, pues, de la norma prescrita en el artículo 329.1. del Real Decreto legislativo 781/1986, de 18 de abril, por el que se aprueba el Texto Refundido de las disposiciones legales vigentes en materia de Régimen Local, es la de lograr la adecuación de las actividades con el ordenamiento urbanístico, independientemente de la exigencia de que precise su demolición.

Queda, respecto a la finalidad de la norma, la precisión establecida en el párrafo segundo del propio artículo 329 del Real Decreto legislativo $781 / 1986$, al calificar este recargo como usancionador".

La consideración a realizar respecto a ello es obvia: ¿Cómo puede considerarse el recargo como sancionador, sobre unas actividades que hasta el momento del cambio de ordenación urbanística eran adecuadas a la misma? Las edificaciones o activida- 
des, cuando fueron levantadas eran adecuadas al planeamiento, sus propietarios se sometieron a la legalidad urbanística vigente en ese momento. El hecho de que el nuevo plan o las ordenanzas de edificación las califiquen de inadecuadas no significa que en todos los supuestos tal calificación sea debida a la negligencia de sus propietarios. Por ello habría que distinguir las diferentes situaciones que pueden darse.

$\mathrm{Y}$ en el caso de que consideremos que entran dentro del juego del artículo 329.1..$^{\circ}$ del Real Decreto legislativo 781/1986 los usos considerados como fuera de ordenación, tal declaración no lleva consigo la desaparición inmediata del mismo, ya que, como ha establecido la jurisprudencia, "seguirá existiendo y prestando el servicio para el que fue erigido hasta que llegue el momento de su desaparición, bien por consunción como tal, bien por llevarse a efecto las previsiones del plan urbanístico» (Sentencias del Tribunal Supremo, Sala IV, de 24 de mayo de 1977 y 7 de febrero de 1986).

\section{INTERPRETACION DE LOS CONCEPTOS DE LA NORMA}

El primer párrafo del artículo 329 no llega a precisar con claridad los conceptos que propone, con lo que resulta ser una norma oscura y difusa.

3.1. De un lado, lo que se entiende por «establecimientos industriales».

El término, interpretado en un sentido estricto, restringido o literal, nos llevaría a dejar fuera del mismo términos como los de instalaciones, almacenes, comercios o cualquier otra actividad no industrial en el sentido dado al concepto. De esta forma, puede entenderse que el término establecimiento o actividad es mucho más amplio y engloba a todos los que hemos citado; y, así, todo establecimiento industrial es una actividad, pero no toda actividad es un establecimiento industrial.

En este sentido restringido, el recargo no sería aplicado a aquellas actividades o establecimientos que, aun cuando estuvieran emplazados fuera de las zonas señaladas a tal fin por los Planes u Ordenanzas, fueran considerados como no industriales.

Sin embargo, no es ésta la interpretación que habrá que dar a la norma. Si el propio artículo se remite al Reglamento de Ac- 
tividades Molestas, Insalubres, Nocivas y Peligrosas, de 30 de noviembre de 1961, éste en su artículo $10^{\circ}$ engloba bajo la denominación de actividades, a las instalaciones, establecimientos, actividades, industrias o almacenes, sean oficiales o particulares. Luego establecerá que de éstos quedan sujetos al propio reglamento aquellos que produzcan incomodidades, alteren las condiciones normales de salubridad e higiene del medio ambiente y ocasionen daños a la riqueza pública o privada o impliquen riesgos graves para las personas o los bienes.

Recogiendo, pues, esta interpretación amplia, dentro del concepto señalado en el artículo 329 del Real Decreto legislativo 781/ 1986, quedarían englobadas todas las actividades (instalaciones, establecimientos, actividades, industrias o almacenes) estuvieran sujetas o no al propio Reglamento de Actividades Molestas, Insalubres, Nocivas y Peligrosas.

$\mathrm{Y}$ así parece reconocerlo también el Tribunal Supremo cuando señala que en este artículo quedan englobadas las «actividades comerciales o industriales» (Sentencia de 6 de marzo de 1987).

No obstante, hay que señalar que ello requiere de unas matizaciones que se examinarán con posterioridad.

3.2. El artículo 329.1..$^{\circ}$ del Real Decreto legislativo 781/1986 trata de los establecimientos que estuvieren emplazados "fuera de las zonas señaladas para tal fin en los planes y normas urbanísticas, o en las ordenanzas reguladoras de las actividades molestas, insalubres, nocivas y peligrosas».

Hay que comenzar señalando que en las Ordenanzas Municipales reguladoras de las citadas actividades no suele establecerse propiamente una zonificación, no siendo tampoco esta determinación una obligación a contener en las mismas, a tenor de lo dispuesto en la normativa de actividades molestas, insalubres, nocivas y peligrosas (la Orden ministerial de 11 de marzo de 1963 que desarrolla el Reglamento de 30 de noviembre de 1961, en su artículo $1 .^{\circ}$, al configurar el contenido de dichas Ordenanzas, no precisa la obligatoriedad de establecer una zonificación, propia de los Planes de Urbanismo).

Para delimitar, por ello, qué son establecimientos emplazados fuera de las zonas señaladas, hay que recurrir a la Ley del Suelo, o, en virtud de la misma, a los Planes de Ordenación y Normas Urbanísticas, junto con las Ordenanzas de editicación. 
El concepto del artículo 329 parece aludir, a su vez, por un lado, a los edificios e instalaciones (industrias) erigidos con anterioridad a la aprobación del Plan General o Parcial que resultaren disconformes con el mismo (es decir, calificados como fuera de ordenación) y regulados en el artículo 60 del Texto Refundido de la Ley del Suelo de 9 de abril de 1976; y, de otro, a las instalaciones $o$ industrias existentes en edificaciones inadecuadas de los artículos 154 de la Ley del Suelo y 5.5. del Reglamento de Edificación Forzosa y Registro Municipal de Solares (aprobado por Decreto 635/1964, de 5 de marzo).

A ello se añade el artículo 61.1. de la Ley del Suelo, el cual establece: «cuando, aprobado un Plan, resultaren industrias emplazadas en zona no adecuada, las edificaciones y sus instalaciones quedarán sujetas a las limitaciones del artículo anterior (es decir, al mismo régimen que los edificios e instalaciones calificados como fuera de ordenación del art. 60) con las tolerancias que de modo general se prevean en las Normas Urbanísticas o en las Ordenanzas de edificación.»

Se manejan, pues, dos conceptos diferentes: el de edificios e instalaciones o establecimientos disconformes con el planeamiento (régimen de fuera de ordenación), y el de aquellos que sean inadecuados.

3.2.1. El primero de ellos, es decir, edificios e instalaciones fuera de ordenación, hay que tratarlo conforme al planeamiento vigente en la localidad, ya que ante un cambio en la ordenación urbana, el órgano competente puede introducir normas en el planeamiento referentes a estas situaciones que tendrán prioridad en su aplicación sobre lo dispuesto en los propios artículos 60 y 61 de la Ley del Suelo. La jurisprudencia lo ha venido entendiendo de esta forma, y así la Sentencia del Tribunal Supremo de 6 de octubre de 1975 indica que la incorporación al nuevo planeamiento de las edificaciones anteriores en una norma coordinadora entre lo edificado al amparo de la normativa anterior y la nueva ordenación, es posible en el ejercicio de las facultades que para el desarrollo de los Planes tienen encomendados los Ayuntamientos, sin que en puridad pueda hablarse de enfrentamiento del mando imperativo propuesto con lo preceptuado en el artículo 60 del Texto Refundido.

El Plan de Urbanismo puede introducir en su contenido normas referentes a las edificaciones y usos erigidos o establecidos con 
anterioridad a su aprobación que tendrán prioridad aplicativa respecto del artículo 60 de la Ley del Suelo, ya que tiene como finalidad armonizar situaciones discrepantes, incorporando edificaciones o usos anteriores o prever las medidas idóneas para incorporarlos al nuevo régimen urbanístico a través de la tolerancia permitida.

Lo anterior, hay que ponerlo en relación para el supuesto de industrias con lo preceptuado en el artículo 61 al establecer que "cuando, aprobado un Plan, resultaren industrias emplazadas en zona no adecuada, las edificaciones y sus instalaciones quedarán sujetas a las limitaciones del artículo anterior, con las tolerancias que de modo general se prevean en las Normas Urbanísticas o en las Ordenanzas de edificaciones».

Habrá que admitir, por tanto, estas tolerancias, y estar a lo dispuesto en las Normas del Planeamiento. Y así, si se trata de actividades permitidas, con carácter general, no podrán prohibirse aun cuando se trate de industrias situadas en lugar no adecuado. (Diversas sentencias del Tribunal Supremo han venido a ratificar estos criterios. Así, la de 17 de diciembre de 1974 señala que procederá la concesión de licencia de apertura de establecimiento en edifiico fuera de ordenación, siempre dentro de las limitaciones impuestas al inmueble.)

Se desprende la existencia de una "graduación» en la consideración de los usos calificados como fuera de ordenación, dada la posibilidad que se atribuye al Plan para regularizar usos tolerados o bien de establecer un régimen especial para las edificaciones y usos fuera de ordenación, distinto del preceptuado en los ar. tículos 60 y 61 de la Ley del Suelo, debiendo determinarse qué se entiende por uso tolerado. Función ésta que corresponde determinar a cada Plan concreto.

Estos usos tolerados, si bien pueden considerarse como usos "disconformes", en sentido amplio, con el planeamiento, sin embargo, no quedan englobados en el contenido del artículo 329.1. En primer lugar, porque no pueden considerarse como establecimientos emplazados fuera de las zonas señaladas para tal fin en los planes y normas, ya que el uso concreto en esas zonas está permitido, aunque, y ése es el problema, con unas limitaciones que los usos tolerados rebasan.

En segundo lugar, el Plan puede permitir realizar en ellos obras que exceden de las señaladas o permitidas en el artículo 60.2. 
de la Ley del Suelo, en virtud de la potestad de planeamiento reconocida a la Administración y a la que se ha aludido. La finalidad del Plan, pues, en cuanto a estos usos no es la de que desaparezcan en el menor tiempo posible, sino lo contrario, de hacerlos compatibles con el planeamiento y que se extingan, en todo caso, por la propia vida normal del uso o establecimiento.

La necesaria coordinación precisa no sólo entre los diferentes órganos y entes administrativos, sino también entre aquellas regulaciones normativas que expresan conceptos a través de una remisión a normas ajenas, lleva consigo la estimación a la que se ha llegado; estos usos no quedarán incluidos dentro del artículo 329 del Real Decreto legislativo 781/1986, de 18 de abril.

3.2.2. Se ha señalado anteriormente que este artículo 329 parecía remitirse también a otro concepto reflejado en la legislación urbanística: el de edificaciones o instalaciones inadecuadas del artículo $154.3 .^{\circ}$ de la vigente Ley del Suelo, y así lo viene a reflejar también el propio Tribunal Supremo cuando en su Sentencia de 6 de marzo de 1987 se refiere a actividades comerciales o industriales inadecuadas a la ordenación urbanística.

El artículo $154.3 .^{\circ}$ de la Ley del Suelo trata, entre otras, de las fincas en donde existiesen construccíones «inadecuadas al lugar en que radiquen" a efectos de considerarlas como solares, y lo mismo expresa el artículo 4..$^{\circ}$ del Reglamento de Edificación Forzosa y Registro Municipal de Solares, aprobado por Decreto 635/ 1964, de 5 de marzo.

Para determinar qué se entiende por edificaciones o usos inadecuados debemos remitirnos al artículo 5.5. del Reglamento citado, al señalar que lo serán las que se hallen en algunas de las situaciones siguientes:

A) Aquéllas cuyo volumen sea inferior al 50 por 100 del mínimo autorizado por las Ordenanzas de Edificación en relación con la superficie aprovechable.

B) Las que en más de un 50 por 100 de su volumen o de la superficie construida estén destinadas a uso urbanístico contrario al previsto por la Ordenanza de Edificación vigente en el momento de su calificación.

C) Las que, además de estar en manifiesta desproporción con la altura legalmente autorizada y corriente en la zona, desmerezcan por su estado, condición o clase de las demás del sector. Se estimarán causas de tal desmerecimiento: El mal estado de conser- 
vación y el incumplimiento de los requisitos de volumen, uso, alineaciones y servicios higiénicos. No podrán alegarse a efectos excusatorios que dichas circunstancias concurren en otras fincas del sector; $y$

D) Las edificaciones provisionales que se estimaren inadecuadas, salvo lo dispuesto en los artículos 58 y 60 de la Ley del Suelo y disposiciones concordantes.

Para determinar aquellas instalaciones sujetas al artículo 329 del Real Decreto legislativo $781 / 1986$, debe ponerse, pues, en relación los conceptos de «fuera de ordenación» e «inadecuadas».

Hay que precisar, en primer lugar, que no pueden equipararse los dos conceptos, aun cuando el artículo 61 de la Ley del Suelo parece confundirlos cuando trata de «industrias emplazadas en zona no adecuada".

Así, para que un edificio o instalación se considere fuera de ordenación bastará la disconformidad con el planeamiento vigente, mientras que la inadecuación se refiere a lo que debe ser el edificio o la instalación, teniendo en cuenta el lugar en que radica.

Diversas sentencias del Tribunal Supremo señalan con precisión la distinción entre ambos conceptos. Así, la Sentencia de 1 de julio de 1964 señala: La Ley se expresa con amplitud al exigir la inadecuación no actualmente, ni en la calle o manzana en que esté situado el edificio, sino en relación al lugar en que radique, lo que exige un pronunciamiento, previa apreciación de las circunstancias del caso concreto, y si no bastaran las consideraciones anteriores, el espíritu que informa la ordenación de solares, y la más reciente Ley del Suelo de 1956, conduciría también a desechar la interpretación que se formula en la demanda, porque sería contrario a aquel espíritu cuanto represente limitar el ritmo de aplicación de aquellas normas, que respondiendo a una política de ordenación urbana fundada en la función social de la propiedad, intenta resolver situaciones de emergencia, fomentando la edificación en relación directa con eí ornato público y el conflicto de la escasez de viviendas, fines todos cuya realización urgente se frustraría, si por un excesivo respeto al interés privado fuera sacrificado al mismo el interés público y general; sin que sea obstáculo a tal conclusión lo preceptuado en el artículo 60 de la Ley del Suelo, comprendido en el Capítulo III sobre «Efectos de la aprobación de los planes», Sección primera, "Publicidad, ejecutoriedad y obligatoriedad», formulados de un concepto distinto 
al previsto en el artículo 154, cual es el de disconformidad con el Plan de Ordenación, que no implica de suyo la inadecuación, ya que edificios modernos y perfectos desde el punto de vista urbanístico pueden comprenderse en tal calificación con sólo pensar en un cambio de alineación o en una modificación de las Ordenanzas municipales, mientras que la inadecuación se pronuncia en relación a lo que debe ser el edificio, teniendo en cuenta el lugar en que radica.

Y la Sentencia de 14 de enero de 1975 señala: Son distintos los supuestos de «inadecuación» y «fuera de ordenación» de un edificio, con consecuencias jurídicas diversas, tal como ha declarado la doctrina de la Sala en sentencias, entre otras, de 30 de abril de 1965, 16 de noviembre de 1968 y 11 de noviembre de 1970, porque aunque una finca fuera de ordenación pueda ser al mismo tiempo «inadecuada», ambas figuras o calificaciones jurídicas no son necesariamente simultáneas ni coincidentes, ni sus regímenes jurídicos, en todo caso, intercambiables.

Ahora bien, como se señala, ello no quiere decir que ambos conceptos sean incompatibles, ya que pueden darse edificios o instalaciones fuera de ordenación que además sean inadecuadas. La base fáctica que engendra su aplicación puede tener cabida en ambos. Así, la Sentencia del Tribunal Supremo de 8 de abril de 1965 señala que: Distintos son, por responder a necesidades de casos diferentes, los supuestos contemplados por el legislador en los artículos 60 y 154 del Texto Refundido de la Ley del Suelo de 9 de abril de 1978 (se han actualiazdo los artículos de la Ley de 1956, por ser su redacción análoga). Las diversas consecuencias de dichos supuestos no implican que la base fáctica que engendra su aplicación no pueda tener cabida en ambos; puede darse el caso, y de hecho con frecuencia se da, de edificaciones e instalaciones erigidas con anterioridad al Plan General o Parcial, que al mismo tiempo que contrarias al mismo "fuera de ordenación» son «inadecuadas» al lugar en que radique, la elección de la norma en tales casos para regir su situación corresponderá a aquella persona a quien va dirigida, el que realice las obras o propietario, al que no se puede compeler a seguir camino distinto al que estiman más beneficioso para sus derechos o cuando éste está legalmente autorizado. 


\section{CONCLUSIONES}

Para determinar, pues, los establecimientos emplazados fuera de las zonas señaladas para tal fin en los Planes y Normas Urbanísticas podrían adoptarse diversas conclusiones, aunque a la vista de la normativa citada y del contenido posible de los Planes podrían considerarse los siguientes criterios interpretativos del artículo 329 del Real Decreto legislativo 781/1986:

4.1. Excluir del concepto del artículo 329 del Real Decreto legislativo 781/1986 a los usos considerados como tolerados según los Planes Generales y también a aquellos que, aun considerándose como fuera de ordenación pueden regularizarse mediante el establecimiento de medidas correctoras o restricciones en el uso que hagan posible su consideración como permitido o tolerado.

4.2. Se consideran incluidos los usos que hayan sido declarados expresamente fuera de ordenación por los Planes Generales o por los Planes Parciales o Especiales que en desarrollo de los mismos puedan redactarse; así como aquellos que estén afectados por viales, zonas verdes o equipamientos previstos en los Planes que resulten incompatibles con el uso previsto, y los que incumplan las limitaciones de uso establecidas en los Planes Generales cuando no sea posible la implantación de medidas correctoras.

4.3. Los establecimientos y usos considerados como inadecuados, a tenor de lo especificado en los artículos 61 y $154.3 .^{\circ}$ de la Ley del Suelo y 5.5. del Reglamento de Edificación Forzosa y Registro Municipal de Solares deberán también considerarse incluidos en el artículo 329, con las precisiones realizadas en los puntos anteriores.

4.4. Resta, por último, realizar una consideración eminentemente práctica.

Será preciso que los Ayuntamientos realicen $\rho$ redacten catálogos o censos de establecimientos calificados como fuera de ordenación o inadecuados, con las graduaciones anteriormente precisadas; trabajo éste imprescindible y previo para llevar a cabo la implantación del recargo sobre el Impuesto de Radicación que pretende el artículo 329 del Real Decreto legislativo 781/1986.

De otra parte, si la finalidad de norma es extrarrecaudatoria o de lograr el traslado de aquellos establecimientos o actividades 
a zonas adecuadas, deberá existir el suficiente suelo industrial y en las condiciones idóneas o adecuadas que permitan el traslado de las mismas y no su simple desaparición o extinción del mundo industrial o comercial. 